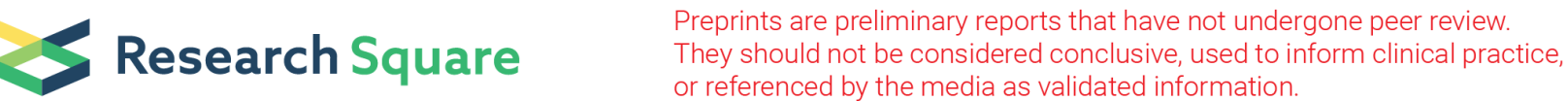

\section{Investigation, Analysis and Management Application of Mental Resilience and Psychosomatic State of The Medical Team Against COVID-19}

\author{
Xiao-li xu \\ Affiliated Jingling hospital,Medical School of Nanjing University \\ Li Guangyao \\ psychological counseling center,904 hospital \\ Huang Shunhong \\ The 910th Hospital of PLA \\ Liu Bin \\ The Second Military Medical University \\ Zhang Sibing ( $\sim$ zsb2020tg@163.com )
}

\section{Research}

Keywords: coronavirus-19 (Covid-19), the medical team, mental resilience, the psychosomatic state

Posted Date: June 5th, 2020

DOl: https://doi.org/10.21203/rs.3.rs-29149/v1

License: (c) This work is licensed under a Creative Commons Attribution 4.0 International License.

Read Full License 


\section{Abstract}

Objective: to understand the mental resilience and psychosomatic status quo of first-line anti-epidemic medical team members, so as to provide a reference basis for mastering the mental health status of medical team members and promoting the improvement of mental resilience.

Methods: a cluster sampling method was used to conduct mobile phone questionnaire survey on the selected subjects using the staff status questionnaire and Chinese version of mental resilience scale (Chinese version of cd-risc).

Results: the total score of mental resilience of the medical team was $65.40 \pm 13.90$ points higher than that of the Chinese community. However, the tenacity of men was higher than that of women $(P<0.05)$. In terms of psychosomatic state influence score, the psychosomatic influence of first-line task on women was greater than that on men $(P<0.01)$.

Conclusion: the anti-epidemic task has a great influence on the psychosomatic state of the first-line medical personnel, and the first-line medical personnel should be provided with better social and psychological support. Frontline medical personnel should be good at actively seeking social support and learn to adopt a positive way of coping.

\section{Background}

Novel coronavirus (2019-ncov) pneumonia (covid-19) currently has no specific treatment drugs and means, and the infectivity of the virus is relatively strong [1], which will inevitably cause a greater impact on the physical and mental health of the first-line medical personnel fighting covid-19. Good mental resilience helps individuals to calmly deal with pressure and reduce negative emotions. The calmness and control shown by individuals with good mental resilience in the face of difficulties and the mental toughness to recover easily after emergency trauma are all favorable factors to ease occupational stress [2]. The purpose of this paper is to investigate the mental resilience and psychosomatic status of the firstline medical workers fighting the epidemic, so as to provide reference for the timely grasp of the physical and mental health status of the first-line medical workers fighting the epidemic and promote their mental resilience.

\section{Materials And Methods Research object}

From March 3 to March 5, 2020, a medical team participating in first-line medical rescue in wuhan was selected as the research object. The actual sample size was 160 cases, among which 156 cases were effective samples, with an effective sample rate of $97.5 \%$. Among the 156 cases investigated, 77 were male $(49.4 \%)$ and 79 were female $(51.6 \%)$. The average age was $(36.5 \pm 8.50)$. There were 22 cases with junior college degree or less (14.1\%), 97 cases with bachelor's degree (62.2\%), and 37 cases with master's 
degree or above (23.7\%). There were 43 doctors (27.6\%), 78 nurses (50.0\%), and 35 staff (22.4\%). 23 people have worked for 5 years or less (14.7\%), 64 people have worked for $6-15$ years $(41.0 \%)$, and 69 people have worked for more than 15 years (44.2\%).

\section{Research methods}

Methods and tools a mobile phone questionnaire survey was conducted on the selected subjects by means of cluster sampling. Prepare staff status questionnaire and Chinese version of mental resilience scale (Chinese version of cd-risc). The self-compiled staff status questionnaire was designed according to the research purpose and content, mainly collecting the following contents: gender, age, culture, marital status, job type, working years, and psychological symptoms and subjective feelings related to the work of fighting against the epidemic. The Chinese version of cd-risc contains 25 items, three factors (tenacity, strength and optimism), and is rated on a scale of 0 to 4 . The theoretical median value of the scale is 50 , and the higher the score, the better the mental resilience.

Before the quality control assessment, the psychological expert shall review the assessment tools and items item by item, and standardize the guidance language to prevent misunderstanding. Ask to be measured when assessment besides name, general data and topic must answer complete, ask to be measured to answer according to oneself actual condition, do not communicate with the person, complete independently inside specified time. If any information is found to be incomplete, please complete it.

Statistical processing original data database was established by Excel 2007. SPSS19.0 software package was used for statistical processing, chi-square test was used for inter-group comparison of classified variable data, independent sample t test or analysis of variance was used for inter-group comparison of continuous variable data, and LSD method was used for posterior pantwise comparison. In the bilateral significance test, $\mathrm{P}<0.05$ was considered as statistically significant.

\section{Results}

Comparison of psychological resilience of epidemic prevention personnel with different genders, occupations and educational levels. The results showed that the total score of mental resilience of the medical team was $65.40 \pm 13.90$ points higher than that of the Chinese community. However, the tenacity of men was higher than that of women $(P=0.048)$, as shown in table 1 . The tenacity of the service staff was higher than that of the medical staff $(\boldsymbol{P}=\mathbf{0 . 0 4 9})$, as shown in table 2 . In terms of psychosomatic state influence score, the psychosomatic influence of first-line anti-epidemic task on women was greater than that on men, as shown in table 3. There was no significant correlation between mental resilience and educational level, as shown in table 4.

Comparison of psychosomatic state between different genders. The results showed that there was no statistically significant difference between male and female except for the item of "self-perception" $(\boldsymbol{P}=\mathbf{0 . 0 8 4})$. In terms of "fatigue sense", "sleep condition" and "psychosomatic influence", the proportion of 
males with corresponding conditions was lower than that of females, with statistically significant differences $(\boldsymbol{P}<0.001, P=0.045,0.025)$. As shown in table 5 .

Comparison of psychosomatic state of epidemic prevention workers of different positions. The results showed that there was no statistically significant difference in the "sleep condition" among the epidemic prevention personnel of different positions ( $P=0.395)$. In terms of "self-feeling", "sense of fatigue" and "psychosomatic influence", there were statistically significant differences among epidemic prevention workers of different levels $(\boldsymbol{P}<0.01)$. The results are shown in table 6. 
Table 1. Comparison of mental resilience of epidemic prevention personnel of different genders ( $X \pm s$ )

\begin{tabular}{|c|c|c|c|c|}
\hline Project & Male $(n=77)$ & Female $(n=79)$ & $t$ & 0.675 \\
\hline Optimism & $11.44 \pm 2.628$ & $11.27 \pm 2.600$ & 0.420 & 0.282 \\
\hline Power sex & $25.47 \pm 5.313$ & $24.61 \pm 4.614$ & 1.080 & 0.048 \\
\hline Toughness & $38.14 \pm 8.419$ & $35.47 \pm 8.305$ & 1.997 & 0.129 \\
\hline The total score & $75.05 \pm 15.700$ & $71.34 \pm 14.646$ & 1.527 & 0 \\
\hline
\end{tabular}

Table 2. Comparison of mental resilience of epidemic prevention workers of different duties ( $X \pm s$ )

\begin{tabular}{|c|c|c|c|c|c|}
\hline Project & physicians $(n=43)$ & nurse $(n=78)$ & Service personnel $(n=35)$ & F & 0.534 \\
\hline Optimism & $11.26 \pm 2.226$ & $11.18 \pm 2.647$ & $11.89 \pm 3.445$ & 0.113 \\
\hline Power sex & $24.60 \pm 4.435$ & $24.49 \pm 4.874$ & $27.17 \pm 6.410$ & 2.218 \\
\hline Toughness & $37.05 \pm 6.662$ & $35.31 \pm 8.421 *$ & $40.61 \pm 11.205$ & 3.076 \\
\hline The total score & $72.91 \pm 12.664$ & $70.97 \pm 15.058$ & $79.67 \pm 15.303$ & 2.414 & 0.049 \\
\hline
\end{tabular}

*Compared with the service staff, $P<0.05$

Table 3. Psychosomatic status of epidemic prevention personnel of different genders on their own influence degree

\begin{tabular}{|c|c|c|c|c|c|c|}
\hline \multirow[t]{2}{*}{ Project } & \multicolumn{2}{|c|}{ Male $(n=77 \square$} & \multicolumn{2}{|c|}{ Female $(n=79 \square$} & \multirow[t]{2}{*}{$\chi^{2}$} & \multirow[t]{2}{*}{$P$} \\
\hline & $\mathrm{n}$ & $\%$ & $\mathrm{n}$ & $\%$ & & \\
\hline No effect & 29 & 37.7 & 13 & 16.5 & 10.204 & $=0.006$ \\
\hline Mild & 38 & 50.6 & 48 & 60.8 & & \\
\hline Moderate & 9 & 11.7 & 18 & 22.8 & & \\
\hline
\end{tabular}


Page 6/14 
Table 4. Comparison of psychological resilience of epidemic prevention personnel with different educational levels( ' $X \pm s$ )

\begin{tabular}{c|c|c|c|c|c|}
\hline Project & $\begin{array}{c}\text { College degree or } \\
\text { below }(\mathrm{n}=22)\end{array}$ & $\begin{array}{c}\text { bachelor degree } \\
(\mathrm{n}=97)\end{array}$ & $\begin{array}{c}\text { master degree or } \\
\text { above }(\mathrm{n}=37)\end{array}$ & F & 0.247 \\
\hline Optimism & $11.68 \pm 3.604$ & $11.34 \pm 2.512$ & $11.19 \pm 2.184$ & 1.533 & 0.219 \\
\hline Power & $26.59 \pm 6.500$ & $24.97 \pm 4.842$ & $24.27 \pm 4.154$ & 0.707 & 0.495 \\
\hline Tenacity & $38.77 \pm 11.259$ & $36.49 \pm 8.435$ & $36.38 \pm 6.352$ & 0.879 & 0.417 \\
\hline The total score & $77.05 \pm 20.453$ & $72.80 \pm 15.059$ & $71.84 \pm 11.829$ & 0.789 \\
\hline
\end{tabular}

Table 5. Status comparison of epidemic prevention personnel of different genders

\begin{tabular}{|c|c|c|c|c|c|c|}
\hline \multirow[t]{2}{*}{ Project } & \multicolumn{2}{|c|}{ Male $(\mathrm{N}=77 \square$} & \multicolumn{2}{|c|}{ Female $(\mathrm{N}=79 \square$} & \multirow[t]{2}{*}{$c^{2}$} & \multirow[t]{2}{*}{$P$} \\
\hline & $\mathrm{n}$ & $\%$ & $\mathrm{n}$ & $\%$ & & \\
\hline \multicolumn{7}{|l|}{ Feel } \\
\hline Good & 43 & 55.8 & 30 & 38.0 & 2.993 & 0.084 \\
\hline Poor & 34 & 44.2 & 42 & 62.0 & & \\
\hline \multicolumn{7}{|l|}{ Fatigue } \\
\hline Tired & 31 & 40.3 & 55 & 69.6 & 16.020 & $\square 0.001$ \\
\hline Fair or not tired & 46 & 59.7 & 21 & 30.4 & & \\
\hline \multicolumn{7}{|l|}{ Sleep } \\
\hline Good & 30 & 39.0 & 19 & 24.1 & 4.024 & 0.045 \\
\hline Poor & 47 & 61.0 & 60 & 75.9 & & \\
\hline \multicolumn{7}{|c|}{ Mind and body are affected } \\
\hline Had an impact & 49 & 63.6 & 63 & 79.7 & 4.998 & 0.025 \\
\hline No effect & 28 & 36.4 & 16 & 20.3 & & \\
\hline
\end{tabular}


Table 6. Comparison of status of epidemic prevention personnel of different duties

\begin{tabular}{|c|c|c|c|c|c|c|c|c|}
\hline \multirow[t]{2}{*}{ Project } & \multicolumn{2}{|c|}{ physicians $(\mathrm{N}=43 \square$} & \multicolumn{2}{|c|}{ nurse $(\mathrm{N}=78 \square$} & \multicolumn{2}{|c|}{ Attendant $(\mathrm{N}=35)$} & \multirow[t]{2}{*}{$c^{2}$} & \multirow[t]{2}{*}{$P$} \\
\hline & $\mathrm{n}$ & $\%$ & $\mathrm{n}$ & $\%$ & $\mathrm{n}$ & $\%$ & & \\
\hline \multicolumn{9}{|l|}{ Feel } \\
\hline Good & 20 & 46.5 & 28 & 35.9 & 29 & 82.8 & 13.315 & 0.001 \\
\hline Poor & 23 & 53.5 & 50 & 64.1 & 6 & 17.2 & & \\
\hline \multicolumn{9}{|l|}{ Fatigue } \\
\hline Tired & 17 & 39.5 & 58 & 74.4 & 10 & 28.5 & 21.265 & $\square 0.001$ \\
\hline Fair or not tired & 26 & 60.5 & 20 & 25.6 & 25 & 71.5 & & \\
\hline \multicolumn{9}{|l|}{ Sleep } \\
\hline Very good & 16 & 37.2 & 21 & 26.9 & 14 & 40.0 & 1.856 & 0.395 \\
\hline Poor & 27 & 62.8 & 57 & 74.1 & 21 & 60.0 & & \\
\hline \multirow{2}{*}{\multicolumn{9}{|c|}{$\begin{array}{l}\text { Mind and body } \\
\text { are affected }\end{array}$}} \\
\hline & & & & & & & & \\
\hline Iimpact & 30 & 69.7 & 64 & 82.1 & 16 & 45.7 & 11.005 & 0.004 \\
\hline No effect & 13 & 30.2 & 14 & 17.9 & 10 & 54.3 & & \\
\hline
\end{tabular}

The level of mental resilience of medical teams is generally higher than that of social norms.

The results showed that the level of mental resilience of the medical team was higher than that of the social norm. Although previous studies have shown a significant correlation between mental resilience and occupational stress[3], in this task, the mental and physical well-being of personnel of different genders and different levels were significantly affected, resulting in a higher proportion of insomnia and a greater sense of mental and physical fatigue. It may be related to the high intensity and long time of this task and the corresponding risks. Previous studies also suggest that the occurrence of psychological problems is not only related to the individual's own psychological quality, but also closely related to the individual's living environment[4]. Therefore, it is necessary to strengthen the psychological support, strengthen the sleep management and propaganda. At the same time, as medical personnel, they should 
take the initiative to seek self-adjustment means, especially when they are far away from their relatives, they should pay more attention to mobilize their own social support system, which can adjust individuals' bad emotions, share responsibilities, provide advice and material assistance [5], so as to reduce their own pressure and trouble.

\section{Men are generally more resilient than women.}

Mental resilience determines people's ability to cope with stress. Individuals with high mental resilience have a low degree of psychological trauma, rapid recovery and high success rate in coping with negative events [6-8]. Toughness than women, according to the results of male $(P=0.048)$, prompted in performing such tasks in men and response to adapt to the environment will be better than women, the state and the staff in the questionnaire in "fatigue" and "sleep" and "psychosomatic impact" on entry, both men appeared in proportion to the corresponding condition below the situation of the women. This is highly correlated with the conclusion that the depression and anxiety of the outpatient women and nursing staff with fever in hospitals were more serious during SARS [9], which is similar to the previous research results [10]. It suggests that women need better protection and more psychological care in the process of performing tasks. In the results of mental resilience of different levels, the tenacity of the service staff was higher than that of the medical staff $(P=0.049)$. It may be related to the high frequency and intensity of the training received by the service personnel, which is consistent with the result that the mental resilience level of the medical personnel is higher than the social norm. It is suggested that the training of psychological adaptability should be strengthened in the future training. This study shows that there is no significant difference in mental resilience among different educational backgrounds, which is inconsistent with previous studies [11].

\section{The overall psychosomatic state of doctors is better than that of nurses.}

The results of the comparison of the status of epidemic prevention personnel of different positions showed that the difference of "self-feeling", "fatigue feeling" and "psychosomatic influence" was statistically significant $(P<0.01)$. It shows that different jobs have different effects on self-perception and psychosomatic, which may be related to different work intensity and gender composition. Nurses were 61.5 percent more likely to say they were "working hard" than doctors 39.5 percent. The mental and physical condition of doctors is generally better than that of nurses, which may be related to the high working intensity, high pressure and long working time in the contaminated area. The difference of physical and psychological symptoms between doctors and nurses may be related to the work content, physical characteristics and high sensitivity to pressure of nurses. The proportion of doctors choosing "treatment helplessness" in the face of distress was $37.2 \%$, and that of nurses was $20.5 \%$. It may be related to the high proportion of male doctors, strong competitiveness, and the great responsibility of doctors to treat, so doctors should pay more attention to psychological construction, let them realize that the treatment of helplessness is the cause of the disease itself, not their own inability or not to do their best. Studies have shown that it is an effective scientific method to extend the task period to make overall planning of task division, achieve the optimal allocation of human resources, and give team members 
necessary rest by turns [12]. In similar tasks, we should more reasonably set the proportion of medical care, appropriately increase the number of nurses, increase the frequency of nurses' rotation, organize appropriate activities and sports, and strengthen the protection of occupational protection.

\section{Discussion}

\section{Strengthen daily psychological construction and training}

The smooth execution of any task, people are the key and important factor, all the management of the foothold is also a person, so from the beginning of the selection of personnel should be well coordinated professional needs, personality characteristics, psychological adjustment ability and management ability and other factors. In order to quickly build a team with strong psychological quality and able to deal with complex situations in urgent tasks, the most important way to achieve this is to pay attention to the cultivation and training of psychological quality in daily training, and to exercise personal psychological quality in training.

\section{The organic combination of psychology and management}

In this action, management and psychology were well combined. According to different time points, we organized activities such as "good voice against epidemic", "photography exhibition against epidemic" and "blessing to goddess against epidemic", and equipped with fitness equipment according to local conditions, which relieved our mood and boosted our morale. In addition, the theory of psychology is integrated into every detail of management, which makes both management and care equal, rigid and flexible combination, and better coordinate the relationship between organizational needs and individual needs.

\section{Give play to the role of information technology}

The characteristics of this outbreak determined that many work could not be carried out in a conventional way. Therefore, information means played an important role in the psychological and management of this task. The investigation of the status of medical team members and the intervention activities were carried out through the network. In the research process, the network implementation makes the feedback faster and the information more accurate, and avoids the "face" problem common in the routine research. In addition, the network interaction not only meets the requirements for the prevention and control of infectious diseases but also strengthens the interaction, enhances the social support of team members, and minimizes the difficulty of psychological construction caused by the prevention and control of infectious diseases.

\section{Provide humanistic care according to task progress}

Through the staff status questionnaire, dynamic understanding of the psychological needs of team members, to do a good job in humanistic care. At the beginning of the mission is mainly to do a good job of security and life assurance, so that the team members more centering, more at ease. During the task, 
pay attention to understand the mental and physical state of the team members, adjust the work arrangement according to the situation, organize appropriate activities and do a good job of sleep health management. After a long period of tasks, people are prone to psychological fatigue. Therefore, it is necessary to strengthen the management of job burnout, establish a set of smooth channels for communication and communication, and timely understand the team members' thoughts and dynamics through different ways and make targeted management method adjustments. Provide team members with necessary rest by turns, timely reminder and morale encouragement. While ensuring rest, enrich the cultural life of team members as much as possible. Cultural life should be diversified and multi-selected, providing a platform for everyone to find their own way to relax. In order to overcome and cope with "bebo's law", the level and mode of safeguard should be released in stages according to the possible time of the task. In addition, making good use of festivals and birthdays to strengthen team building, so that the team members feel warm, is also a good way of humanistic care.

\section{Conclusion}

In summary, COVID-19 has a certain influence on the psychosomatic state of medical team members participating in the anti-epidemic mission due to its strong infectivity, fast transmission speed and long duration. This study suggests that managers help improve the social support of team members, strengthen organizational management, life security and daily psychological counseling. At the same time, medical team members should also take the initiative to seek help, actively deal with, strengthen communication and alleviate the psychological impact caused by stress.

\section{Abbreviations}

COVID-19

Coronavirus disease 2019

\section{Declarations}

\section{Availability of data and materials}

The data in the study is real and available

\section{Acknowledgements}

The authors greatly appreciate the staff of all medical team members for their cooperation and the staff of the Military Medical Research editorial office for their hard work.

\section{Funding}

national social science fund key project 17AGL024

\section{Authors' information}


Xu Xiaoli*, Li Guangyao*, Huang Shunhong, Liu Bin, Zhang Sibing

Xu Xiaoli, Li Guangyao contributed equally to this work.

Affiliations

Affiliated Jinling Hospital, Medical School of Nanjing University, Nanjing 210002, China;

First author: Xu Xiaoli*, Chief physician

Psychological counseling center, 904 hospital, master of medicine, Changzhou, 213003, China;

Li Guangyao*, associate chief physician

The 910th hospital of the PLA; Quanzhou, 362000, China;

Huang Shunhong

The Second Military Medical University, Shanghai, 200433, China ;

Liu Bin

General Hospital of PLA, Beijing 100853,China;

Zhang Sibing

*These authors contributed equally to this work.

Corresponding author: Zhang Sibing ang Liu Bin

\section{Authors' contributions}

*These authors contributed equally to this work.

Corresponding author

Correspondence to Zhang Sibing or Liu Bin

Ethics declarations

Ethical Approval and Consent to participate

Not applicable.

\section{Consent for publication}

Informed consent was obtained from all individual participants included in the study. 


\section{Competing interests}

The authors declare that they have no conflict of interest.

\section{References}

1. Yang Y, Lu QB, Liu MJ. Epidemiological and clinical features of the 2019 will be coronavirus outbreak in China [J]. J Medrxiv, 2020. https://doi.org/10.1101/ 2020.02.10.20021675.

2. Donna L, Magtibay SS, Chesak K, Coughlin. Amit Sood.Decreasing stress and burnout in nurses: efficacy of blended learning with stress management and resilience training program[J].J Nurs Adm. Jul/Aug. 2017;47(7-8):391-5. doi:10.1097/NNA.0000000000000501.

3. Liang DRui,H. Yu Lingling. Path analysis on the influence of clinicians' social support,resilience and coping style on their occupational stress [J]. Journal of capital medical university. 2009;40(5):67882. doi:10.3969/j.issn.1006-7795.2019.05.003.

4. Mental Health Service for the Staff Carrying out the Military Operations other than War [J] 10.3969/j.issn.1008-9985.2010.10.022

Yunxiang SXiuhua,T. Wang Tiequan. Mental Health Service for the Staff Carrying out the Military Operations other than War [J]. Hospital administration journal of Chinese People's Liberation Army, 2010, 17 (10): 946-7. doi:10.3969/j.issn.1008-9985.2010.10.022.

5. Plessis MD, Boshoff AB. Authentic leadership, followership, and psychological capital as antecedents of work engagement[J]. Journal of Psychology in Africa 28(1): 26-32. doi: 10.1080/14330237.2018.1438832.

6. 10.1016/j.jpsychires.2009.01.013

Forde LCampbell-Sills,DR, Stein MB. The Demographic and childhood environmental predictors of resilience in a community sample [J]. J Psychiatr Res, 2009, Lancet (12): 1007-1012. doi: 10.1016/j.jpsychires.2009.01.013.

7. Feder SAhmad,A, Lee EJ, Wang Y, Southwick SM, Schlackman E, et al. Earthquake impact in a remote South Asian population: Psychosocial factors and postt-raumatic symptoms [J]. J Trauma Stress. 2010;23(3):408-12. doi:10.1002/jts.20535.

8. Cameron F, Brownie S. Enhancing Resilience in Registered Aged Care Nurses [J]. Australas J Ageing. 2010 Jun;29(2):66-71. doi:10.1111/j.1741-6612.2009.00416.x.

9. Wang Wei L, Jinghong G, Wenbin Z, Lian Lu, Jing, Chen jinli, et al. Investigation of the Mental Health Condition of Medical Staff in Fever Clinic of Military Hospitals [J]. Journal of Nursing. 2004;19(7):14-6. doi:10.3969/j.issn.1001-4152.2004.07.005.

10. Leilei SuQGuo, Kun L, Lin Z, Zhuo C, Lin Xiaoming. Research on Resilience and Influencing factors of Clinical Nurses [J]. Medicine Philosophy. 2013;34(22):68-71.

11. Zhao Yanhong C. Yu. Investigation of mental resilience of clinical nurses and analysis of influencing factors [J]. Journal of Clinic Nursing's Practicality. 2008;3(31):177-9. doi:10.3969/j.issn.20962479.2018.31.139. 
12. Wu Xinjuan L, Yanmei C. Jingli. Discussion on the allocation of nursing staff in SARS wards [J]. J Nurs Manag. 2003;3(5):29-31. doi:10.3969/j.issn.1671-315X.2003.05.014. 